\title{
Can Multi-Detector Computed Tomography Classify (MDCT) Non- Compacted Left Ventricle in Coloration to The Genetic Structure?
}

\author{
MANAL Mohamed Helmy Nabo*
}

\author{
Assistant professor, Al Rayan collage, Al Madina Al Munwara, Saudi \\ Arabia. \\ PhD, MD Pediatric Cardiologist, Teaching Hospital, Sohag university, \\ Egypt.
}

${ }^{*}$ Correspondence:

MANAL Mohamed Helmy Nabo, Assistant professor, Al Rayan collage, Al Madina Al Munwara, Saudi Arabia., PhD, MD Pediatric Cardiologist, Teaching Hospital, Sohag university, Egypt, E-mail: abod000000@yahoo.com.

Received: 04 May 2019; Accepted: 30 May 2019

Citation: MANAL Mohamed Helmy Nabo. Can Multi-Detector Computed Tomography Classify Non-Compacted Left Ventricle in Coloration to The Genetic Structure?. J Pediatr Neonatal. 2019; 1(1): 1-5.

Keywords

Genetic cardiomyopathy, Heart failure, Arrhythmias, Stroke.

\section{Introduction}

Isolated left ventricular noncompaction (LVNC) is a genetic cardiomyopathy characterized by prominent ventricular trabeculations and deep intertrabecular recesses, or sinusoids, in communication with the left ventricular cavity [1]. The clinical sequelae of these deformities are the syndrome of heart failure, arrhythmias and stroke. Dusek first described the postnatal persistence of spongy myocardium in 1975 pathologically, but Engberding and Bender made the first clinical recognition with two-dimensional (2D) echocardiography in 1984 [2,3]. Three decades later, with only morphologic assessment available and no definitive genetic pathway, isolated left ventricular noncompaction (LVNC) remains a diagnostic and management challenge. In this review, we wish to spot light on how MDCT can visualize the shape and distribution of spongy myocardium clearer than echocardiography.

\section{Echocardiography}

The traditional diagnostic study for evaluation of LVNC is echocardiography $[1,4-7]$. It is still the most common initial test that identifies the characteristic findings of LVNC and may lead to further evaluation. Chin et al. are credited with the first attempt at defining specific criteria for the diagnosis of LVNC [8]. St"ollberger and Finsterer refined the definition as $>3$ trabeculations protruding from the LV wall apical to the papillary muscles, perfused intertrabecular spaces, and a two layered myocardium with the non-compacted layer usually thicker than the compacted myocardium [9]. Subsequent recent studies have used the Jenni criteria to evaluate the presence of LVNC $[4,9]$.
These criteria include a bilayer myocardium, a noncompacted to compacted ratio $>2$ : 1 , communication with the intertrabecular space demonstrated by Doppler, absence of coexisting cardiac abnormalities as coronary abnormality, and presence of multiple prominent trabeculations [10].

There diagnostic criteria were as follows

(1) $>3$ prominent trabecular formations along the left ventricular endocardial border, which are visible in end-diastole, distinct from papillary muscles, false tendons, or aberrant bands, (2) trabeculations move synchronously with the compacted myocardium, (3) trabeculations form the noncompacted part of the two-layer myocardial structure and (4) perfusion of the intertrabecular spaces from the ventricular cavity is present at end-diastole on color- Doppler echocardiography or contrast echocardiography. They suggest the images for evaluation focus on non-tangential short-axis views of the LV apex with special attention to the apico-lateral wall. There are some disadvantages when using echocardiography for the assessment of LVNC. These include the inability in direct visualization of the shape and extension of the non-compacted muscles. The oblique image planes may not give good information of the how non compacted muscles look like. This distribution may be different from one patient to other and may help in further classification according to the result of genetic testing. The shape and distribution of the non-compacted muscles may give idea about the severity and grading of the LVNC in the future which can be easily obtained using MDCT.

There have been case reports in the literature that identify the diagnosis of LVNC by cardiac computed tomography (CT) [11]. The spatial resolution for identification of LVNC is good with cardiac CT $[11,12]$. An advantage of using CT is the capability to 
evaluate the presence of both CAD (Coronary Artery Disease) and LVNC in patient with new heart failure.

The disadvantages of CT imaging are the high radiation exposure and reactions to the contrast dye, including renal failure. The standard use of cardiac CT in evaluation of LVNC is not yet established. But, our hope is detection correlation between the shape and distribution of spongy muscles and the genetic pattern. There are multiple genetic proposals for the phenotypic development of non-compaction [1,13-18]. None of them have been consistently identified how the genetic pattern can affect the shape and distribution of spongy LVNC. In addition, how LVNC can affect the right ventricle resulting in dilation of the right ventricle. There are more than one gene capable of causing LVNC [13]. The identified genes are as follows:

Fbkp1a/Notch pathway. G4.5 gene/TAZ protein. 14-3-3 deletion. ZASP protein. TNNT2 protein. MYH7 protein. TPM1 protein. MYBPC3 protein. ACTC1 protein.

It is established that a thorough three generational family history should be obtained for evaluation of genetic influence. Therefore, if the shape and distribution of the spongy muscle is detected by MDCT the genetic result will be suspected. This patient and his family not yet underwent genetic study and we think the result will be genetic abnormality that will affect the above protein. The surprise will be if this genetic abnormality is repeated in other cases with the same pattern of spongy muscles. The screening of additional family members is mandatory as the LVNC runs in families $[1,13,14,16]$. A systematic review by Bhatia et al. identified a familial occurrence rate of $30 \%$ in family members that were screened based on an index case [19]. Oechslin and Jenni have proposed an acquired pathogenesis in patients with prior normal cardiac structure and function that develop LVNC later in life. This supports the hypothesis that LVNC may represent a morphologic continuum of genetic cardiomyopathies, including dilated and hypertrophic cardiomyopathies [20]. Sporadic occurrence is thought to account for up to $60-70 \%$ of the cases [18]. In addition, LVNC has association with Barth syndrome, mitochondrial disorders and myotonic dystrophy [13].

\section{Our Case}

A full-term female baby was born by normal vaginal delivery. The baby suddenly develops severe respiratory distress in the first day of life. On examination, there were tachypnea and tachycardia. Abdominal examination show hepatomegaly. Ross classification for heart failure was 8. The X-ray was done and shows cardiomegaly and congested lungs (Figure 1). The cardiothoracic ratio was $67 \%$. The patient was admitted in the nursery care as diagnosed as heart failure. Urgent cardiac consultation was ordered. Echocardiography was done (Figure 2a). The diagnosis was non-compaction of the left ventricle. Sever tricuspid regurge (Figure 3) and pulmonary hypertension. The tricuspid valve shows ballooning of the leaflets with prolapsing into the right atrium (Figure 4). Diuretics were started. The dose was $1 \mathrm{mg} / \mathrm{kg} /$ day. On the next day, there were much improvement and the baby start to have uninterrupted mouth feeding. Follow up X-ray show good aeration of the lung with decrease in lung opacities (Figure 5). Past history was taken from the mother. Two years back, a similar condition was happened. The previous baby was Barth syndrome. The genetic study was done and found there is G4.5 gene/TAZ protein.

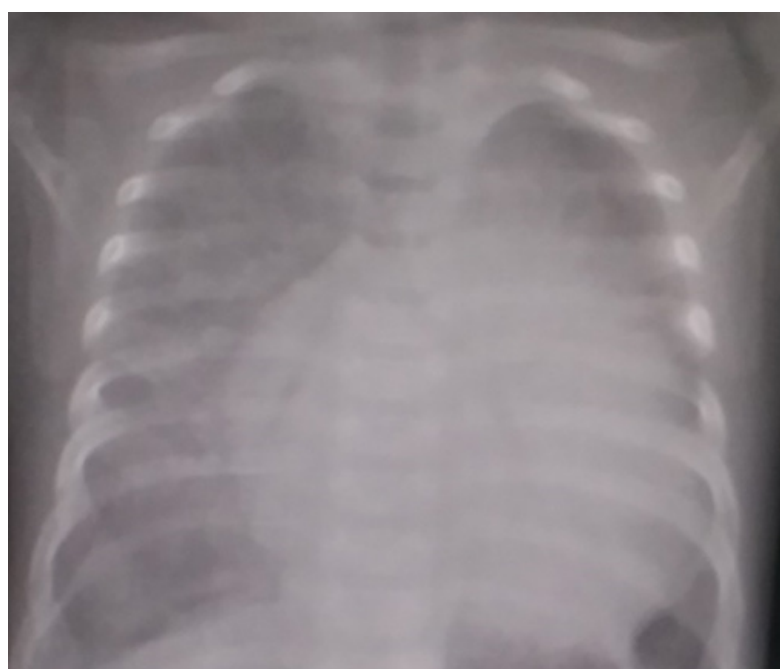

Figure 1: The $\mathrm{x}$ - ray on admission shows cardiomegaly and congested lungs.
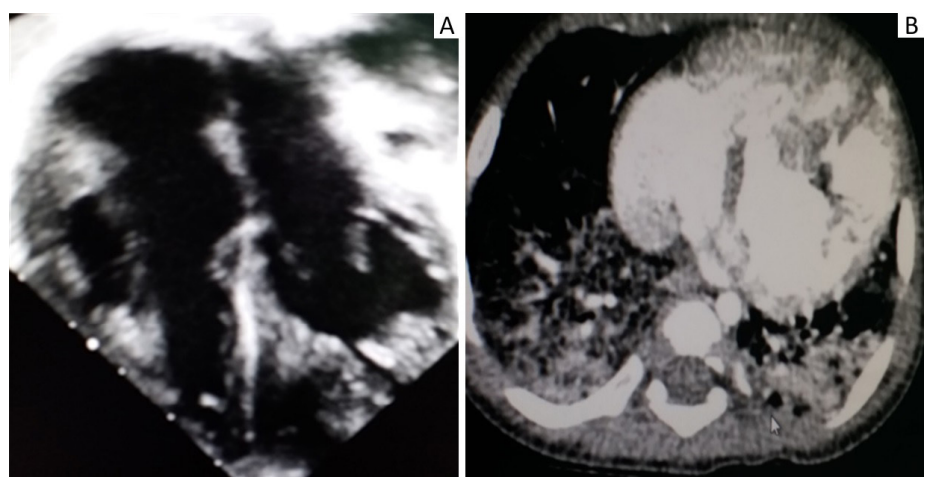

Figure 2: A- Apical four chamber shows hypertrophy of the left ventricle and dilated right side. The exact shape and distribution of the noncompacted muscles cannot be will delineated. B- MDCT can delineate the distribution, shape and extension of the non-compacted muscles in the left ventricle. The muscles look like a root with a steak.

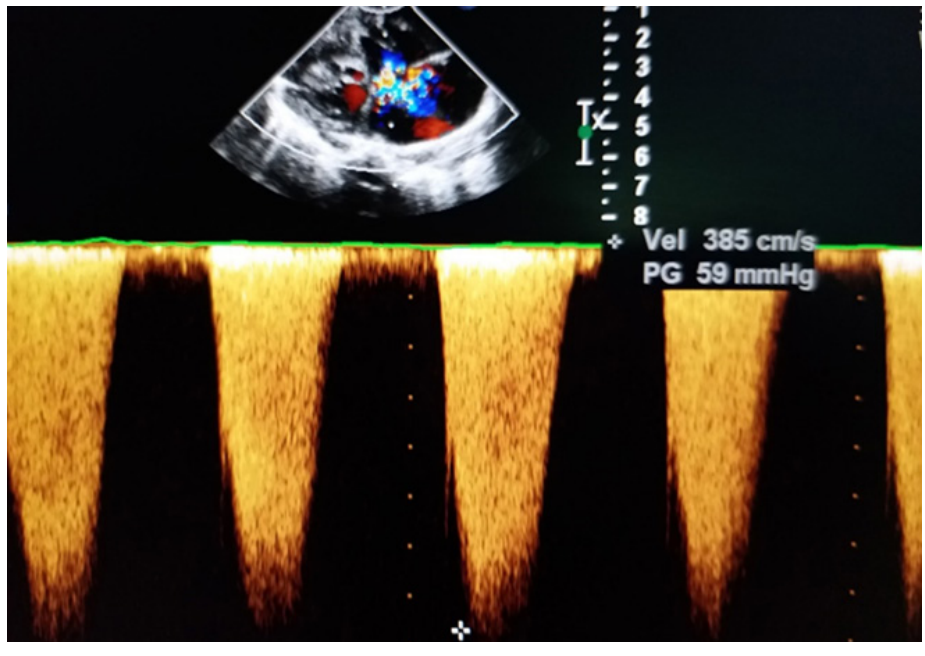

Volume 1 | Issue 1 | 2 of 4 
Figure 3: Tricuspid valve shows regurgitation moderate to sever.

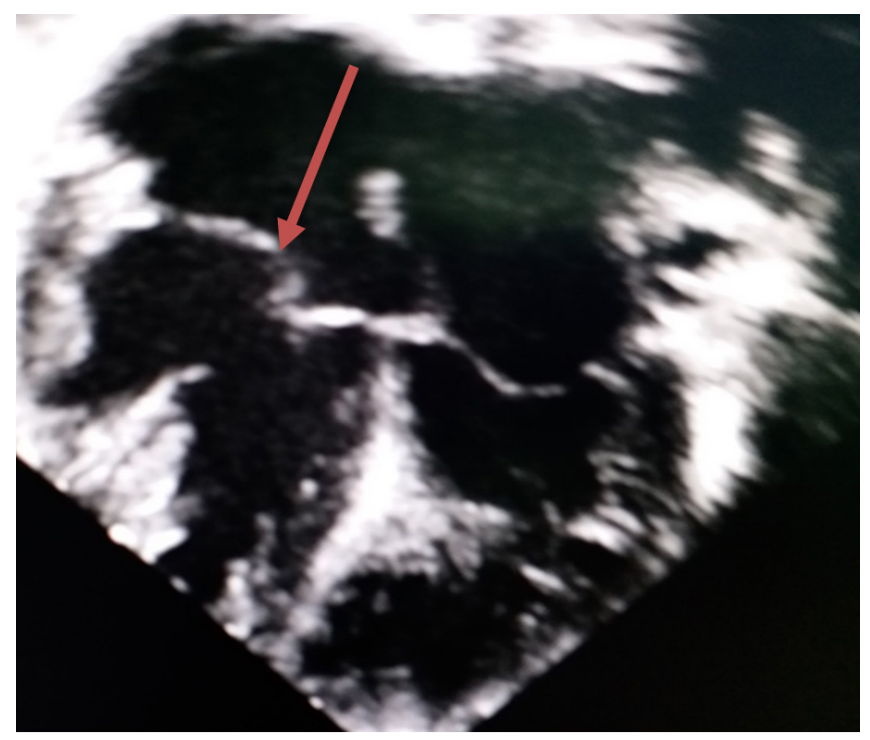

Figure 4: Tricuspid valve shows ballooning and prolapsing in the right atrium (Red Arrows).

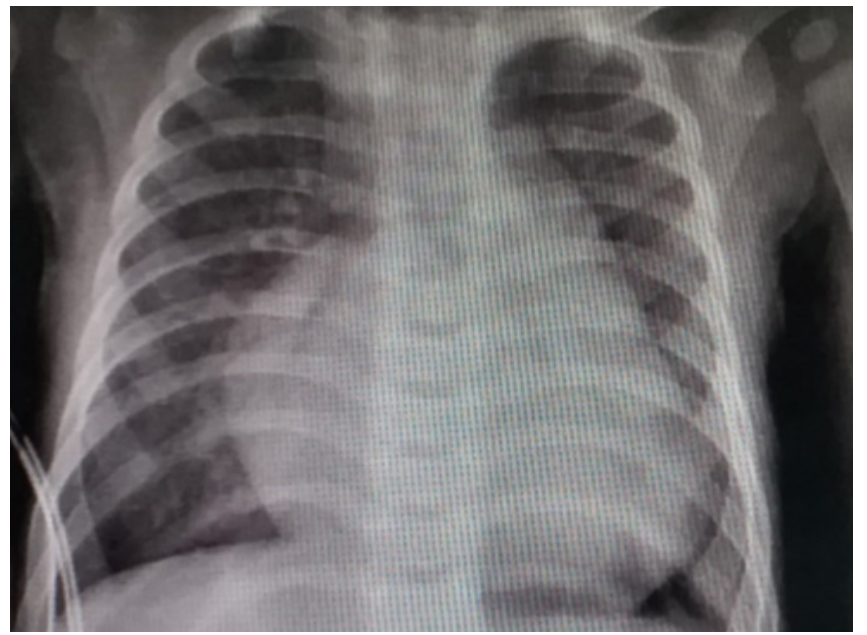

Figure 5: The lungs are aerated well. The $X$ ray two days later as the patient started diuretics.

Unfortunately, the previous baby suddenly died during stay in the nursery care on the third day of life. The suscpion for the newly delivered baby will be the same syndrome is highly indicated. Therefore, serous observation was in mind by all pediatric staff.

Follow up echocardiography was done. Both the systolic and diastolic function of left ventricle were preserved. The friction shorting around $25 \%$ and the ejection fraction were $68 \%$.

The advance in the new technology named multi detector computed tomography (MDCT) was introduce recently in the diagnosis of congenital heart disease. It has a great role in the diagnosis of the intra cardiac and extra cardiac structures. The anomalies of the coronary arteries are easily detected by MDCT. The cardiomyopathy caused by abnormal coronary artery should be carefully excluded. In this case the MDCT shows normal right and left coronaries (Figure 6).

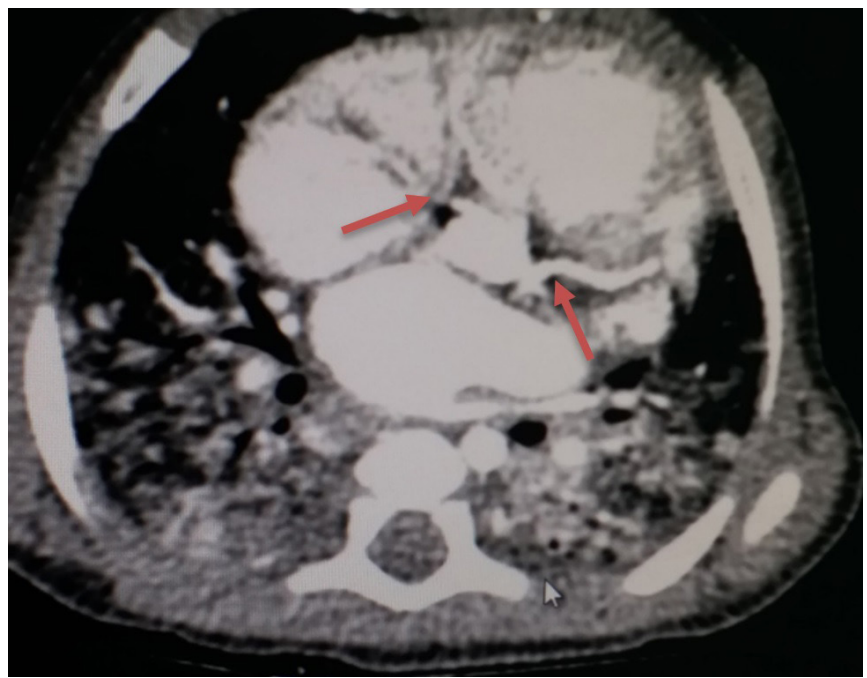

Figure 6: MDCT at the level of the aortic valve. Both the right and left coronaries are clear (red arrows).

After much improvement of the baby. MDCT examination was done and analysis of the images were done. In (Figure $2 b$ ) there were much trabeculation and easily counting the intra-cardiac recess. The diagnosis of LVNC syndrome is confirmed by St"ollberger and Finsterer refined the definition as $>3$ trabeculations protruding from the LV wall apical to the papillary muscles, perfused intertrabecular spaces, and a two layered myocardium with the non-compacted layer usually thicker than the compacted myocardium [21]. In figure 7 more than three recess were seen. In comparison with echocardiography (figure 8) these recesses are not clear.

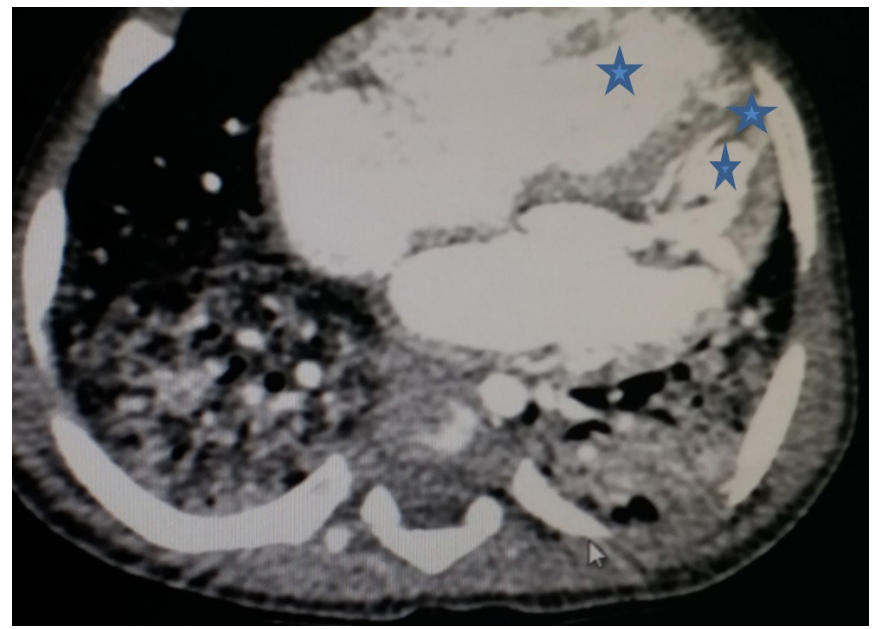

Figure 7: The MDCT at the level of the two ventricles shows the smooth shape of the right ventricle $\left(^{*}\right)$ and the abnormal trabeculations $(* *)$ on the left ventricle.

There diagnostic criteria were as follows: (1) $>3$ prominent trabecular formations along the left ventricular endocardial border, which are visible in end-diastole, distinct from papillary muscles, false tendons, or aberrant bands, (2) trabeculations move synchronously with the compacted myocardium, (3) trabeculations 
form the noncompacted part of the two-layer myocardial structure and (4) perfusion of the intertrabecular spaces from the ventricular cavity is present at end-diastole on color-Doppler echocardiography or contrast echocardiography clearly seen or counted as in figure 8 The small capacity of the left ventricle will effect on the right side result in right atrium dilation and ballooning of the tricuspid valve (Figure 4). Pulmonary hypertension is one of the complications of LVNC syndrome and one of the leading causes of irreversible damage of the pulmonary bed and limited gas exchange.

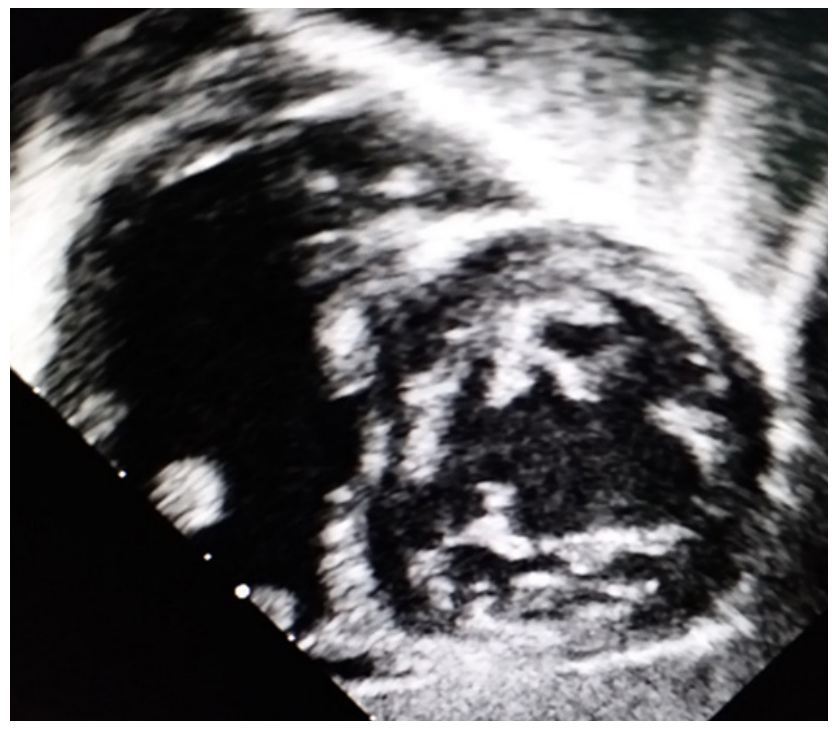

Figure 8: The left venricle shows sever hpertrophy of the myocardium. The cavity is small in left sided ventricle in comparison with the right ventricle cavity.

\section{References}

1. Maron Bj, Towbin JA, Thiene G, et al. Contemporary definitions and classification of the cardiomyopathies: an American heart association scientific statement from the council on clinical cardiology, heart failure and transplantation committee; quality of care and outcomes research and functional genomics and translational biology interdisciplinary working groups; and council on epidemiology and prevention. Circulation. 2006; 113: 1807-1816.

2. Dusek J, Ostadal B, Duskova M. Postnatal persistence of spongy myocardium with embryonic blood supply. Archives of Pathology. 1975; 99: 312-317.

3. Engberding R, Bender F. Identification of a rare congenitalanomaly of the myocardium by two-dimensional echocardiography: persistence of isolated myocardial sinusoids. The American Journal of Cardiology. 1984; 53: 1733-1734.

4. Habib G, Charron P, Eicher JC, et al. Isolated left ventricular non-compaction in adults: clinical and echocardiographic features in 105 patients. Results from a French registry. European Journal of Heart Failure. 2011; 13: 177-185.

5. St"ollberger C, Gerecke B, Finsterer J, et al. Refinement of echocardiographic criteria for left ventricular noncompaction. International Journal of Cardiology. 2013; 165: 463-467.
6. Saleeb SF, Margossian R, Spencer C T, et al. Reproducibility of echocardiographic diagnosis of left ventricular noncompaction. Journal of the American Society of Echocardiography. 2012; 25: 194-202.

7. Jost CHA, Connolly HM. Left ventricular noncompaction: dreaming of the perfect diagnostic tool. European Journal of Heart Failure. 2012; 14: 113-114.

8. Chin TK, Perloff JK, Williams RG, et al. Isolated noncompaction of left ventricular rmyocardium. A study of eight cases. Circulation. 1990; 82: 507-513.

9. St' ollberger C, Finsterer J. Left ventricular hypertrabeculation / noncompaction. Journal of the American Society of Echocardiography. 2004; 17: 91-100.

10. Jenni R, Oechslin E, Schneider J, et al. Echocardiographic and pathoanatomical characteristics of isolated left ventricular non-compaction: a step towards classification as a distinct cardiomyopathy. Heart. 2001; 86: 666-671. 2001.

11. Benjamin MM, Khetan RA, Kowal RC, et al. Diagnosis of left ventricular noncompaction by computed tomography. Baylor University Medical Center Proceedings. 2012; 25: 354-356.

12. Gandhi RT, Sarraf G, Budoff M. Isolated noncompaction of the left ventricular myocardium diagnosed upon cardiovascular multidetector computed tomography. Texas Heart Institute Journal. 2010; 37: 374-375.

13. Finsterer J. Cardiogenetics, neurogenetics, and pathogenetics of left ventricular hypertrabeculation/noncompaction. Pediatric Cardiology. 2009; 30: 659-681.

14. Probst S, Oechslin E, Schuler P, et al. Sarcomere gene mutations in isolated left ventricular noncompaction cardiomyopathy do not predict clinical phenotype. Circulation. Cardiovascular Genetics. 2011; 4: 367-374.

15. Towbin JA. Left ventricular noncompaction: a new form of heart failure. Heart Failure Clinics. 2010; 6: 453-469.

16. Hoedemaekers YM, Caliskan K, Michels M, et al. The importance of genetic counseling, DNA diagnostics, and cardiologic family screening in left ventricular noncompaction cardiomyopathy. Circulation. Cardiovascular Genetics. 2010; 3: 232-239.

17. Teekakirikul P, Kelly MA, Rehm HL, et al. Inherited cardiomyopathies: molecular genetics and clinical genetic testing in the postgenomic era. The Journal of Molecular Diagnostics. 2013; 15: 158-170.

18. Ackerman MJ, Priori SG, Willems S, et al. HRS/EHRA expert consensus statement on the state of genetic testing for the channelopathies and cardiomyopathies this document was developed as a partnership between the Heart Rhythm Society (HRS) and the European Heart Rhythm Association (EHRA). Heart Rhythm. 2011; 8: 1308-1339.

19. Bhatia NL, Tajik AJ, Wilansky S, et al. Isolated noncompaction of the left ventricular myocardium in adults: a systematic overview. Journal of Cardiac Failure. 2011; 17: 771-778.

20. Oechslin E, Jenni R. Left ventricular non-compaction revisited: a distinct phenotype with genetic heterogeneity? European Heart Journal. 2011; 32: 1446-1456. 